\section{Dental appliances with inadequate occlusal coverage: a case report}

\author{
R. A. C. Chate ${ }^{1}$ and D. T. Falconer ${ }^{2}$
}
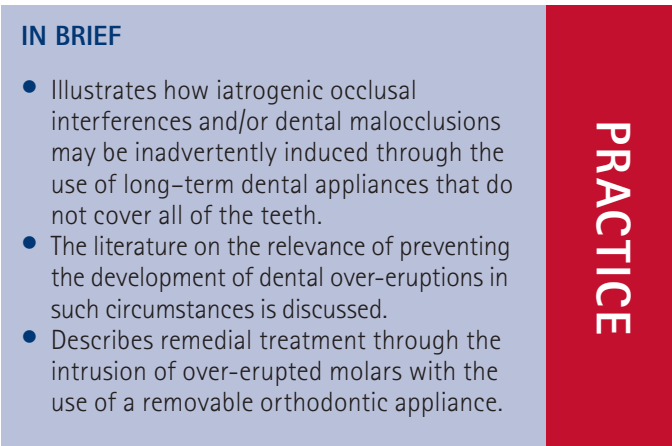

A case is presented which illustrates the occlusal problems that can develop when a dental appliance such as a temporomandibular splint with incomplete occlusal cover is worn for a reasonable length of time. As in this case, the selective overeruption of posterior teeth not incorporated in the appliance can lead to the development of an anterior open bite and an increased overjet. A simple orthodontic method to correct the iatrogenic malocclusion through the re-intrusion of the overerupted teeth is shown and the importance of providing long-term dental appliances with full occlusal contact is discussed.

\section{INTRODUCTION}

Several recent studies have shown that in comparison to Hawley orthodontic retainers, thermoplastic vacuum formed retainers are more cost-effective, preferred by the majority of patients ${ }^{1}$ and in selected cases are more effective. ${ }^{2}$

Although Sheridan originally described the design of one such retainer as encompassing only the lower anterior teeth for nocturnal retention, when these are worn full time just over $2 \%$ of cases develop mild anterior open bites as a consequence. ${ }^{3}$ Complete arch coverage for full time wear has therefore more latterly became the norm, classically in conjunction with occlusal equilibration of the splints for open bite prophylaxis. ${ }^{4}$

\section{CASE REPORT}

A 25-year-old female solicitor who had received previous orthodontic treatment that had included the extraction of the upper first permanent premolars together with fixed appliance therapy in both arches had been wearing a lower soft bite raising appliance (BRA) nocturnally for ten years

${ }^{1 *}$ Consultant Orthodontist, ${ }^{2}$ Consultant Oral and MaxilIofacial Surgeon, Orthodontic Department, Lexden Road, Essex County Hospital, Colchester, C03 3NB

*Correspondence to: Dr Rob Chate

Email: chate@rcsed.ac.uk

Tel: +44 (0)1206744621

\section{Refereed Paper}

Accepted 24 August 2010

DOI: 10.1038/sj.bdj.2011.46

${ }^{\oplus}$ British Dental Journal 2011; 210: 109-110 that her general dental practitioner had supplied, primarily as a means of managing her temporo-mandibular joint (TMJ) dysfunction and secondarily as a long term orthodontic retainer. However, the lower second permanent molars had never been completely incorporated within the BRA splint (Fig. 1).

As a result, the distal aspects of these teeth had over-erupted and through the consequential downwards and backwards rotation of the mandible she had developed both an open bite and an increased overjet (Fig. 2). Yet evidence that she had previously had an anterior occlusion could be seen by the presence of occlusal wear facets on her upper incisors and canines.

In this regard she had been referred for treatment to improve her TMJ dysfunction through the correction of her open bite. She was therefore supplied with an upper removable appliance with bilateral posterior bite blocks that were positioned over the upper third molars. These made selective, solitary contact with the distal cusps of the lower second molars whenever she occluded her teeth. Elsewhere, occlusal stops were placed on the remaining upper premolar and molar teeth in order to prevent them from over-erupting during the process of closing the bite (Fig. 3). After six months of maximum part-time wear her lower second molars had been sufficiently intruded to regain her original occlusion (Fig. 4). Although this resulted in an improvement of her TMJ symptoms,

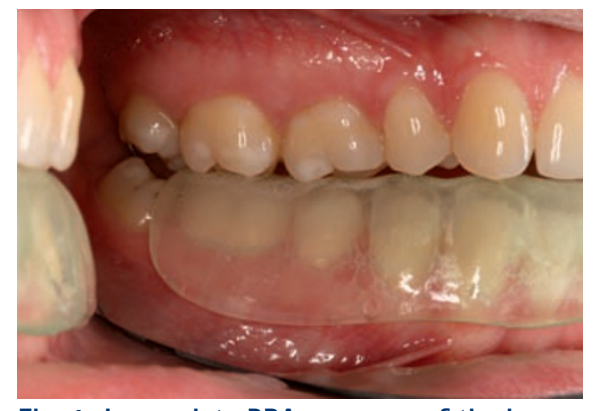

Fig. 1 Incomplete BRA coverage of the lower second molar which has over-erupted on its distal aspect and tipped mesially

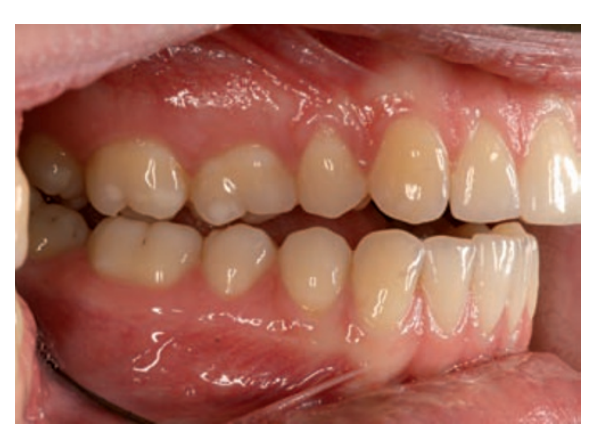

Fig. 2 Occlusal contact between the upper third and over-erupted lower second molar teeth, resulting in a progressive open bite and increased overjet

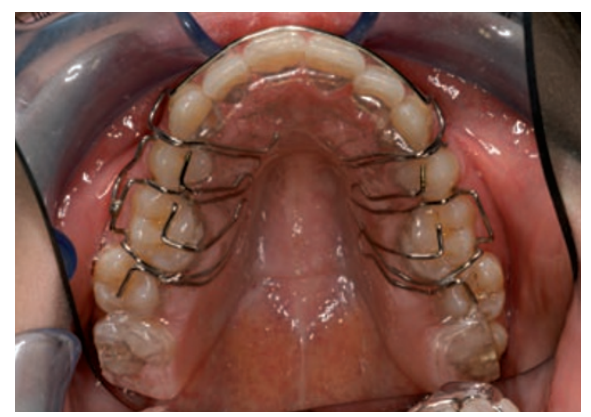

Fig. 3 Occlusal view of the upper removable molar intrusion appliance 


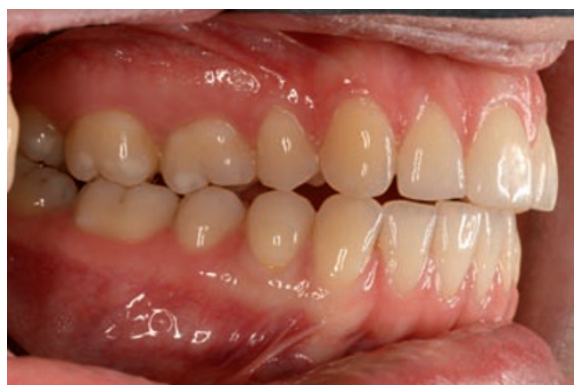

Fig. 4 Recovery of original occlusion

some dysfunction still remained as a consequence of the osteoarthritic changes that were evident on her pre-treatment MRI scan.

\section{DISCUSSION}

The features and treatment of this case both directly and indirectly lend support to a number of previous findings. Namely, if second molars are not routinely included in all stages of orthodontic treatment, including retention, this can result in a higher incidence of non-ideally located posterior contacts. 5

Similarly, orthodontic extraction of upper second molar teeth that leave the lower second molars partially unopposed can also allow the distal aspects of these teeth to subsequently over-erupt and tip. ${ }^{6}$

Indeed, while the potential for completely unopposed adult teeth to over-erupt by up to $5.4 \mathrm{~mm}$ with an incidence of $82-92 \%$ in such circumstances is well documented, ${ }^{7,8,9}$ similar findings have also been demonstrated for teeth that are partially unopposed, albeit with comparatively greater degrees of tipping. ${ }^{10}$

As a consequence, just over a half of all types of over-erupted teeth are involved with either retruded contact position and/ or excursive interferences. ${ }^{9,11}$

Nevertheless, this propensity for adult teeth to erupt when taken out of occlusion is used to good advantage when worn anterior teeth that require space recreation before restoration are initially managed with a Dahl appliance. ${ }^{12}$

\section{CONCLUSION}

This case illustrates why full occlusal coverage of all of the teeth in a dental arch is crucial whenever an appliance is supplied for either prolonged sleep apnoea, ${ }^{13} \mathrm{TMJ}^{14}$ or orthodontic treatment purposes.

Equally, in those circumstances where this has not occurred, the case also shows how localised over-eruptions and associated open bites can be corrected through the use of posterior bite blocks to selectively intrude any over-erupted teeth. ${ }^{15}$

1. Hichens $L$, Rowland $H$, Williams A et al. Costeffectiveness and patient satisfaction: Hawley and vacuum formed retainers. Eur J Orthod 2007 29: 372-378.

2. Rowland $H_{\text {, Hichens }}$, Williams A et al. The effectiveness of Hawley and vacuum-formed retainers: a single-center randomized controlled trial. Am J
Orthod Dentofacial Orthop 2007; 132: 730-737.

3. Sheridan J J, LeDoux W, McMinn R. Essix retainers: fabrication and supervision for permanent retention. J Clin Orthod 1993; 27: 37-45.

4. Sheridan J J, Armbruster P, Moskowitz E, Nguyen P. Avoiding demineralization and bite alteration from full coverage plastic appliances. J Clin Orthod 2001; 35: 444-448.

5. Dincer M, Meral O, Tumer N. The investigation of occlusal contacts during the retention period. Angle Orthod 2003; 73: 640-646.

6. Smith R. The effects of extracting upper second permanent molars on lower second permanent molar position. Br J Orthod 1996; 23: 109-144.

7. Kiliaridis S, Lyka I, Friede H, Carlsson G E, Ahlqwist $M$. Vertical position, rotation, and tipping of molars without antagonists. Int J Prosthodont 2000; 13: 480-486.

8. Craddock H L, Youngson C C. Overeruption in unopposed posterior teeth. Br Dent J 2004; 196: 341-348.

9. Craddock H L, Youngson C C, Manogue M, Blance A Occlusal changes following posterior tooth loss in adults. Part 1: A study of clinical parameters associated with the extent and type of supraeruption in unopposed posterior teeth. J Prosthodont 2007; 16: 485-494.

10. Craddock H L. An investigation of overeruption of posterior teeth with partial occlusal contact. J Oral Rehabil 2007; 34: 246-250.

11. Craddock H L. Occlusal changes following posterior tooth loss in adults. Part 3: A study of clinical parameters associated with the presence of occlusal interferences following posterior tooth loss. $J$ Prosthodont 2008; 17: 25-30.

12. Poyser N J, Porter R W J, Briggs P F A, Chana H S, Kelleher M G D. The Dahl concept: past, present and future. Br Dent J 2005; 198: 669-676.

13. Johal $A$, Battagel J M. Current principles in the management of obstructive sleep apnoea with mandibular advancement appliances. Br Dent $J$ 2001; 190: 532-536.

14. Gray R J M, Davies S J, Quayle A A. A clinical approach to temporomandibular disorders. 6. Splint therapy. Br Dent J 1994; 177: 134-142.

15. Dellinger $E$ L. A clinical assessment of the Active Vertical Corrector--a nonsurgical alternative for skeletal open bite treatment. Am J Orthod 1986; 89: 428-436. 